\title{
Incidence of neurosensory deficits and recovery after lower third molar surgery: a prospective clinical study of 4338 cases
}

\author{
L.K. Cheung ${ }^{1}$, Y.Y. Leung ${ }^{1}$, L.K. Chow ${ }^{1}$, May C.M. Wong ${ }^{2}$, Eugene K.K. Chan ${ }^{1}$, Y.H.Fok ${ }^{1}$ \\ 'Discipline of Oral and Maxillofacial Surgery, \\ ${ }^{2}$ Discipline of Dental Public Health, \\ Faculty of Dentistry, the University of Hong Kong.
}

Address for correspondence:

Professor Lim K. Cheung

Oral \& Maxillofacial Surgery, Prince Philip Dental Hospital

34 Hospital Road, Hong Kong

Tel: +85228590267

Fax: +85228575570

E-mail: 1kcheung@hkucc.hku.hk

Keywords: neurosensory deficit; neurosensory recovery; third molar surgery.

Short title: Neurosensory deficits and recovery after lower third molar surgery 


\begin{abstract}
A prospective study of all lower third molar surgeries performed in the outpatient extraction clinic of a teaching dental hospital was conducted from January 1998 through October 2005 to determine the incidences of subsequent neurosensory deficit due to inferior alveolar nerve (IAN) and lingual nerve (LN) injury, to examine possible contributing risk factors and to describe the pattern of recovery. A total of 3595 patients were included (61\% female, 39\% male; age range, 14-82 years). Of the 4338 lower third molar extractions performed by various grades of operators, 0.35\% developed IAN deficit and 0.69\% developed LN deficit. Distoangular impaction was found to increase the risk of LN deficit significantly ( $p<0.001)$. Depth of impaction was related to the risk of IAN deficit $(p<0.001)$. Undergraduates caused more LN deficit $(p<0.001)$. Sex, age, raising of a lingual flap, protection of $\mathrm{LN}$ with retractor, removal of distolingual cortex, tooth sectioning and difficulty in tooth elevation were not found to be significantly related to IAN or LN injury. Recovery from IAN and LN deficits was noted most significantly at postoperative 3 months and 6 months, respectively. By the end of the follow-up period, $66.7 \%$ of IAN deficit and $72.0 \%$ of $\mathrm{LN}$ deficit had recovered totally.
\end{abstract}

Keywords: neurosensory deficit; neurosensory recovery; third molar surgery 


\section{INTRODUCTION}

Third molar tooth extraction is the most common surgical procedure in the oral cavity, and its major complications include postoperative neurosensory deficits. Studies from different countries have reported on the incidence of various neurosensory deficits after lower third molar tooth surgery $^{1-22,25-55,57}$. For example, inferior alveolar nerve (IAN) injury, which usually presents with paresthesia or anesthesia of the lower lip, chin and buccal gingivae on the affected side, has a reported incidence that ranges from $0.26 \%$ to $8.4 \%{ }^{4,6-8,12-15,22,25,26,28-30,32,37,42-48,51,53}$. Lingual nerve (LN) deficit, which commonly presents with numbness of the ipsilateral anterior two-thirds of the tongue and taste disturbance, has a reported incidence of between $0.1 \%$ and $22 \%{ }^{4,12,13,25,28-}$ $30,32,37,42-46,52$. Neurosensory deficits can markedly affect the quality of life of affected patients ${ }^{18}$. Hence, continuous efforts have been made by researchers to investigate the risk factors associated with nerve injuries in lower third molar surgery. Factors such as the age of the patient, depth of tooth impaction, proximity of the roots to the IAN, surgical experience of the operator and surgical technique have been proposed as being associated with an increased risk of IAN injury ${ }^{4,6-8,12-15,22,25,26,28-30,32,37,42-48,51,53}$.. Perforation of the lingual plate and the lingual bone split technique have been found to be associated with LN damage. It remains unknown, however, whether elevation of the lingual flap and an attempt to protect the LN by an instrument actually increase the risk of LN damage ${ }^{4,12,13,25,28-30,32,37,42-46,52}$.

The aims of this prospective study were to determine the incidences of IAN and LN deficit after surgery for impacted lower third molars in a teaching dental hospital in Hong Kong; to evaluate the risk factors contributing to these postoperative neurosensory deficits; and to examine the pattern of recovery of these neurosensory deficits in affected patients. 


\section{MATERIALS AND METHODS}

This was a prospective clinical study of all lower third molar surgeries performed in the outpatient extraction clinic of the Discipline of Oral and Maxillofacial Surgery at the Faculty of Dentistry, The University of Hong Kong, between January 1998 and October 2005. The study was approved by the Faculty's Ethics Committee and patients gave written informed consent. Patients were excluded if they presented with conditions that were associated with the lower third molars, such as cysts and tumors, or with any preexisting neurosensory deficit related to the IAN and LN. The following data were recorded in a set of questionnaires: (1) preoperative data: sex, age, type of impaction (mesioangular, horizontal, distoangular or vertical), depth of impaction (by measuring the Winter's lines ${ }^{56}$ from standardized orthopantomogram), operator's experience and state of eruption of the lower third molars; (2) intraoperative data: raising of the lingual flap, use of a periosteal elevator to protect the LN, removal of distolingual cortex, tooth sectioning, root fragment elevation, difficulty with tooth elevation and any intraoperative complications.

20 orthopantomograms were selected randomly and the depth of impaction of the lower third molar was measured by an examiner. Reliability test was run between the original and the examiner's measurement and was shown to have no statistical difference. The random error was also found to be within acceptable limit.

All patients were reviewed 1 week after surgery to assess wound healing status and the presence of any neurosensory deficits related to the lower third molar tooth surgery. Self-reported subjective sensory changes were recorded and objective assessments were performed with light touch test (with von Frey fibres), two points discrimination threshold and pin pick pain threshold 
in patients complaining of neurosensory disturbance. They were then monitored regularly to assess the pattern of recovery at post-operative 1 month, 3 months, 6 months, 1 year and 2 years and beyond according to the standardized assessments.

Data were analyzed with the Statistical Package for Social Sciences (SPSS version 11.5; SPSS Inc, Chicago, IL, USA). The independent $t$ test was used to examine whether cases of LN and IAN deficit differed from cases of uneventful healing by mean patient age and depth of impaction. The chi-square test was used to examine whether the incidence of LN and IAN deficits varied according to the following possible risk factors: sex; type of impaction; experience of operator; whether the lingual flap was raised, a periosteal elevator was used as protection and distolingual cortical bone was removed; whether tooth sectioning was needed; and whether there was any difficulty with tooth elevation. The $5 \%$ probability level was taken as the cut-off for statistical significance and a $1 \%$ level was taken as the cut-off for highly statistical significance. 


\section{RESULTS}

\section{Incidence of neurosensory deficits}

A total of 3595 patients were enrolled in this study; $61 \%$ were female and $39 \%$ were male. Their ages ranged from 14 to 82 years (mean, 27.2 years). Of the 4338 impacted mandibular third molars that were surgically extracted, $78.5 \%$ (3407) had partially erupted, $15.5 \%$ (673) were unerupted and the remainder $(6.0 \% ; 258)$ had erupted. The most common type of impaction was mesioangular (47.9\%) and the mean depth of impaction of all types ranged from 3.0 to $6.5 \mathrm{~mm}$ (Table 1). In terms of experience of the dental operator, $45.6 \%$ of the extractions were performed by undergraduate dental students; $40.4 \%$ by junior residents and $11.9 \%$ by oral and maxillofacial surgery (OMS) postgraduates, and $2.1 \%$ by OMS specialists.

Fifteen extractions $(0.35 \%)$ resulted in IAN-related neurosensory deficits and $30(0.69 \%)$ resulted in LN-related neurosensory deficits. The remaining 4293 (98.96\%) extractions did not present with any neurosensory complications.

\section{Risk factors of neurosensory deficits}

\section{Sex and age}

The incidence of IAN deficit in male and female were $0.36 \%(6 / 1672)$ and $0.34 \%(9 / 2665)$, respectively. There was no statistical difference between the gender of IAN deficit $(p=0.99)$ The incidence of LN deficit in male and female were $0.84 \%(14 / 1672)$ and $0.60 \%(16 / 2665)$, respectively. Again there was no statistical difference between the gender of LN deficit $(p=0.66)$. The mean (SD) ages of patients who showed IAN and LN injury were 28.7 (8.6) years and 27.1 
(6.6) years, respectively, and were not significantly different from the mean (SD) age of patients who showed uneventful healing (26.9 [8.4] years, $\mathrm{p}=0.46)$.

\section{Type and depth of impaction}

Although the incidence of IAN deficit for each type of impaction ranged from $0.15 \%$ for vertical to $0.65 \%$ for distoangular, there was no statistical difference in the incidence of IAN deficit according to type of impaction $(\mathrm{p}=0.48)$. In contrast, the incidence of $\mathrm{LN}$ deficit by type of impaction ranged from $0.53 \%$ each for mesioangular and horizontal to $1.9 \%$ for distoangular, and the variation in incidence according to impaction type was highly statistically significant $(\mathrm{p}<0.001 ;$ Table 2$)$.

The mean depth of impaction was greater among lower third molar extraction cases leading to IAN deficit than among those that did not lead to IAN deficit [8.9mm (S.D. 3.5mm) versus 5.0mm (S.D. 3.1mm)]; this difference was highly statistically different $(\mathrm{p}<0.001)$. On the other hand, there was no statistical difference in the mean impaction depth among extractions leading to $\mathrm{LN}$ deficit and those that did not $[5.7 \mathrm{~mm}$ (S.D. $3.4 \mathrm{~mm})$ and $5.0 \mathrm{~mm}$ (S.D. $3.1 \mathrm{~mm}), \mathrm{p}=0.44$, respectively; Figure 1].

\section{Experience of operators}

Most of the LN deficits $(76.7 \% ; 23 / 30)$ occurred after surgeries performed by undergraduate students, whereas IAN deficits most commonly $(53.3 \% ; 8 / 15)$ occurred after surgeries performed by OMS postgraduates The patterns of incidence of IAN and LN injury differed by operator type with high statistical significance $(\mathrm{p}<0.01$ and $\mathrm{p}<0.001$, respectively; Table 3$)$. 
The mean depth of impacted lower third molars ranged from 4.4 to $7.4 \mathrm{~mm}$ and was greatest after extractions that were performed by OMS postgraduates. The impaction depth varied with high significance among the different groups of operators ( $\mathrm{p}<0.001$; Table 3$)$. This finding suggests that the increase in incidence of IAN deficits could be related to the deeper impaction of lower third molars that are likely to be extracted by OMS postgraduates, even though they are surgically better trained than the undergraduates and junior residents.

\section{Raising of lingual flap and lingual nerve protection}

A lingual flap was raised during $32.9 \%(1427 / 4338)$ of surgeries, and an attempt was made to protect lingual tissue with a periosteal elevator during 79.5\% (3447/4338) of surgeries. Of the operations involving a raised lingual flap, $0.91 \%$ (13/1427) led to postoperative LN deficits. In contrast, $0.58 \%(17 / 2911)$ extraction cases of postoperative LN deficit were reported among the operations in which a lingual flap was not raised, but these two proportions were not significantly different $(\mathrm{p}=0.58)$. Of the operations in which a periosteal elevator was placed lingually, $0.73 \%$ $(25 / 3447)$ led to postoperative LN deficits, which was also not statistically significant $(p=0.60)$ from the proportion of operations without periosteal elevator placement that resulted in postoperative LN deficits $(0.56 \% ; 5 / 891)$.

\section{Removal of distolingual cortex}

In about one-fifth $(20.2 \%$; 876/4338) of extractions, the distolingual cortex was removed by bone guttering. LN deficit occurred in $0.91 \%(8 / 876)$ of the surgeries with distolingual cortex removed, while LN deficit occurred in $0.64 \%$ (22/3462) without distolingual cortex removed. There was 
no significant difference in the incidences of $\mathrm{LN}$ deficit between the distolingual cortex removal and the preservation groups $(\mathrm{p}=0.38)$.

\section{Tooth sectioning}

Of the 4338 operations, $2667(61.5 \%)$ required tooth sectioning. Those cases most commonly involved mesioangular $(55.3 \% ; 1475 / 2667)$ and horizontal $(38.7 \% ; 1032 / 2667)$ impaction. The incidences of IAN deficit in groups with and without tooth sectioning were $0.30 \%(8 / 2667)$ and $0.42 \%(7 / 1671)$, respectively. The incidences of LN deficit in groups with and without tooth sectioning were $0.57 \%(15 / 2667)$ and $0.91 \%(15 / 1671)$, respectively. Proportions of extractions that did and did not use tooth sectioning were not significantly different for either the $\operatorname{LN}(p=0.20)$ or IAN groups $(\mathrm{p}=0.52)$.

\section{Difficulty with tooth elevation}

Difficult tooth elevations were reported by the operators in $726(16.7 \%$ of 4338$)$ procedures, of which 9 presented with LN deficit (1.2\%) and $2(0.28 \%)$ presented with IAN deficit postoperatively. Operations not encountering difficulty in tooth elevation had $21 \mathrm{LN}$ deficits $(0.58 \%)$ and 13 IAN deficits $(0.36 \%)$ post-operatively. The incidences in LN and IAN deficit in surgeries encountering tooth elevation did not differ significantly when compared to surgeries without difficulty in tooth elevation ( $p=0.051$ and $p=0.72$ respectively) 


\section{Recovery patterns}

\section{Inferior alveolar nerve}

The 15 patients with unilateral IAN deficit after lower third molar surgery were reviewed postoperatively at 1 week and at 1,3, 6, 12 and 24 months or beyond until resolution of the symptoms. No patients dropped out during the follow-up period, which lasted from 32 to 70 months (mean, 49 months). By the end of follow-up, 10 of the 15 patients $(66.7 \%)$ were deemed to have experienced total recovery (Table 4). Almost half of the patients had recovered by 3 months, and most of those who showed complete recovery had done so by 1 year $(60.0 \% ; 9 / 15)$; only one more patient recovered between 1 and 2 years, and no more patients showed a full recovery after 2 years (Figure 2). The 5 patients who presented with incomplete recovery or persistent numbness beyond 2 years' review were considered to have permanent IAN damage. The rate of permanent neurosensory deficit of the IAN in this study was thus $0.12 \%$.

\section{Lingual nerve}

Four of the 30 patients who had unilateral LN deficit after third molar surgery did not return for any follow-up after the first post-operative review; the drop-out rate was thus $13.3 \%$. The followup duration ranged from 32 to 72 months (mean, 56 months). One patient underwent LN exploration and re-anastomosis in the 13th postoperative month and was excluded from analysis after the 1-year follow-up. Total recovery from the LN deficit was achieved in most patients $(57.7 \% ; 15 / 26)$ within the first 6 postoperative months and in 18 patients at the end of the review

period. Seven patients presented with incomplete recovery or persistent numbness at or beyond 2year review (Table 5). The rate of permanent neurosensory deficit of the LN in this study was thus $0.16 \%$. 


\section{DISCUSSION}

Between 1966 and 2007, at least 35 published prospective studies reported incidences of IAN or LN injury following mandibular third molar surgery (Table 6). To our knowledge, because of its 4338 lower third molar tooth surgeries and 3595 patients, this study has the largest sample reported so far and is the only one that has evaluated the incidence of neurosensory deficits in Hong Kong. We found that the incidences of IAN and LN deficits were $0.35 \%$ and $0.69 \%$, respectively. These figures are among the low end of the prospective studies published, suggesting that the training of lower third molar surgery in the centre has reached the international standard.

Several studies have shown that age is associated with an increased risk of nerve damage in third molar surgeries. Bruce et al. ${ }^{13}$ noted that the risk of nerve damage was significantly higher for patients aged 35 years or older than for those aged 14 to 24 years. Black ${ }^{8}$ concurred that there was a strong association between age and IAN deficit, and recommended removal of third molars before age 20 years. Increasing age has also been shown to be related to an increasing risk of LN injury $^{15,50}$. Some authors have thus suggested germectomy during adolescence to reduce the risk of nerve damage ${ }^{15,16}$. In contrast, some studies have not found a positive correlation between age and risk of nerve injury ${ }^{12,17,29,31,51}$. This study likewise does not support the notion that age imposes an increased risk of IAN and LN deficits from lower third molar surgery. As with most studies in the literature, we found no association between a patient's gender and the risk of IAN and LN deficits. 
Kipp et al. ${ }^{28}$ reported an increased risk of neurosensory deficits after extraction of horizontally impacted lower third molar surgeries compared with other types of impaction. Carmichael and McGowan ${ }^{14}$ reported a similar finding and suggested that vertical impacted lower third molars carried a lower risk of nerve damage. Other studies do not support such conclusion ${ }^{54}$. This study found an association between the impaction pattern and incidence of LN (but not IAN) deficit, with distally impacted lower third molars being at highest risk of LN deficit. This could be due to the large amount of distal bone removal including the lingual cortex to facilitate the path of withdrawal of the tooth and possible inadvertent damage to the LN.

The depth of impaction has also been shown to be a risk factor of nerve injury ${ }^{9,14,22,28,39}$. Kipp et al. and Carmichael and McGowan concluded that full bony impaction has the greatest risk of nerve damage ${ }^{14,28}$, whereas others using the classification system of Pell and Gregory showed that the deeper the impaction is, the higher the risk of IAN damage will be ${ }^{22}$. Using Winter's line ${ }^{56}$ as the measurement of depth in this study, we confirmed that the risk of IAN deficit is increased in third molars of greater depth of impaction. This finding can be explained by the reduced accessibility of the surgery, as well as the closer proximity of the tooth to the IAN in deeply impacted third molars. Yet, LN deficit was not found to be at a statistical significant risk in the deeper impacted lower third molars.

The experience of the clinician performing the surgery is often considered to be a risk factor of nerve damage in lower third molar extraction. Sisk et al. ${ }^{47}$ suggested that the less experience the operator has, the more frequent complications will occur, including LN injury. Valmaseda- 
Castellon et al. ${ }^{52}$ also found a significantly higher rate of LN damage among first-year surgical trainees than among third-year surgical trainees. In agreement, Jerjes et al. ${ }^{27}$ noted a higher risk of both IAN and LN injury among third molar extractions performed by junior operators. This study found that dental undergraduates caused more LN deficits than postgraduate operators with more experience. However, our OMS postgraduates had the highest incidence of IAN deficit among the operators, which is probably because in our teaching hospital, deeply impacted teeth and more challenging cases are assigned to OMS postgraduates. In support of this reason, we found a significant association between impaction depth and operator type, with postgraduates dealing with the deepest third molars.

It has been a continuous debate over the past decade whether raising a lingual flap during lower third molar surgery and placement of a sub-periosteal retractor will protect the $\mathrm{LN}$ or damage the LN unintentionally. In 2001, Pichler and Beirne ${ }^{34}$ concluded in a systematic review that the use of a lingual tissue retractor during third molar surgery could induce a higher risk of temporary nerve damage than when a retractor was not used; however, there was no difference between the two groups in terms of permanent LN damage. Pogrel and Goldman ${ }^{35}$ subsequently recommended lingual retraction to improve surgical access because their prospective study of 2004 found no increased risk of permanent LN damage when retraction was used. Gomes et al. ${ }^{20}$ confirmed in a split mouth randomized clinical trial in 2005 that there was a significant increase in the risk of temporary LN injury by lingual retraction. In this study, we did not find any statistical difference in incidence of LN deficit from either lingual flap raising or protection of the LN. 
Many reports have reported that the patterns of recovery from IAN and LN deficits after third molar surgery are similar. In general, neurosensory deficits after third molar surgery spontaneously recover in the first 6 postoperative months ${ }^{2,9,27,28,57}$. Hillerup noticed a significant improvement in $66 \%$ of IAN deficit associated with third molar surgery ${ }^{23}$. We concur that more than $50 \%$ of patients with IAN or LN deficits achieve total recovery by the 6-month follow-up. The frequency of sensory improvement gradually increased after 6 months but no further cases of total recovery could be found after 2 postoperative years also concurring with the finding of Hillerup $^{24}$. The incidence of permanent sensory disturbance was $0.12 \%$ and $0.16 \%$ for IAN and LN injury, respectively. These rates are low when compared with incidences of permanent IAN and LN deficit reported in the literature $\mathrm{1}^{1,3-11,13,14,18-22,25,27,29-31,33,38-43,48,49,51,52,57}$.

\section{DECLARATIONS}

Funding: None

Competing Interests: None

Ethical Approval: Not required

None of the authors have any commercial associations, supporting funds, or financial disclosures. 


\section{REFERENCES}

1. Absi EG, Shepherd JP. A comparison of morbidity following the removal of lower third molars by the lingual split and surgical bur methods. Int J Oral Maxillofac Surg 1993: 22: 149-153.

2. Alling $\mathrm{CC} 3^{\text {rd }}$. Dysesthesia of the lingual and inferior alveolar nerves following third molar surgery. J Oral Maxillofac Surg 1986: 44: 454-457.

3. Appiah-Anane S, Appiah-Anane MG. Protection of the lingual nerve during operations on the mandibular third molar: a simple method. Br J Oral Maxillofac Surg 1997: 35: 170172.

4. Bataineh AB. Sensory nerve impairment following mandibular third molar surgery. J Oral Maxillofac Surg 2001: 59: 1012-1017.

5. Bell CW. Use of dental panoramic tomographs to predict the relation between mandibular third molar teeth and the inferior alveolar nerve. Radiological and surgical findings, and clinical outcome. Br J Oral Maxillofac Surg. 2004: 42:21-27.

6. Benediktsdottir IS, Wenzel A, Petersen JK, Hintze H. Mandibular third molar removal: risk indicators for extended operation time, postoperative pain, and complications. Oral Surg Oral Med Oral Pathol Oral Radiol Endod 2004: 97: 438-446.

7. Berge TI, Bøe OE. Predictor evaluation of postoperative morbidity after surgical removal of mandibular third molars. Acta Odontol Scand. 1994: 52:162-169.

8. Black CG. Sensory impairment following lower third molar surgery: a prospective study in New Zealand. N Z Dent J 1997: 93: 68-71.

9. Blackburn CW, Bramley PA. Lingual nerve damage associated with the removal of lower third molars. Br Dent J 1989: 167: 103-107.

10. Blondeau F. Paresthesia: incidence following the extraction of 455 mandibular impacted third molars. J Can Dent Assoc. 1994: 60: 991-994

11. Blondeau F, Daniel NG. Extraction of impacted mandibular third molars: postoperative complications and their risk factors. J Can Dent Assoc. 2007: 73: 325.

12. Brann CR, Brickley MR, Shepherd JP. Factors influencing nerve damage during lower third molar surgery. Br Dent J 1999: 186: 514-516.

13. Bruce RA, Frederickson GC, Small GS. Age of patients and morbidity associated with mandibular third molar surgery. J Am Dent Assoc 1980: 101: 240-245. 
14. Carmichael FA, McGowan DA. Incidence of nerve damage following third molar removal: a West of Scotland Oral Surgery Research Group study. Br J Oral Maxillofac Surg 1992: 30: 78-82.

15. Chiapasco M, De Cicco L, Marrone G. Side effects and complications associated with third molar surgery. Oral Surg Oral Med Oral Pathol 1993: 76: 412-420.

16. Chossegros C, Guyot L, Cheynet F, Belloni D, Blanc JL. Is lingual nerve protection necessary for lower third molar germectomy? A prospective study of 300 procedures. Int J Oral Maxillofac Surg 2002: 31: 620-624.

17. Fielding AF, Rachiele DP, Frazier G. Lingual nerve paresthesia following third molar surgery: a retrospective clinical study. Oral Surg Oral Med Oral Pathol Oral Radiol Endod 1997: 84: 345-348.

18. Gargallo-Albiol J, Buenechea-Imaz R, Gay-Escoda C. Lingual nerve protection during surgical removal of lower third molars. a prospective randomised study. Int $\mathrm{J}$ Oral Maxillofac Surg. 2000: 29: 268-271

19. Goldberg MH, Nemarich AN, Marco WP 2nd. Complications after mandibular third molar surgery: a statistical analysis of 500 consecutive procedures in private practice. $\mathrm{J}$ Am Dent Assoc 1985: 111: 277-279.

20. Gomes AC, Vasconcelos BC, de Oliveira e Silva ED, da Silva LC. Lingual nerve damage after mandibular third molar surgery: a randomized clinical trial. J Oral Maxillofac Surg 2005: 63:1443-1446.

21. Greenwood M, Langton SG, Rood JP. A comparison of broad and narrow retractors for lingual nerve protection during lower third molar surgery. Br J Oral Maxillofac Surg 1994: 32:114-117.

22. Gulicher D, Gerlach KL. Sensory impairment of the lingual and inferior alveolar nerves following removal of impacted mandibular third molars. Int J Oral Maxillofac Surg 2001: 30: $306-312$.

23. Hillerup S. Iatrogenic injury to the inferior alveolar nerve: etiology, signs and symptoms, and observations on recovery. Int J Oral Maxillofac Surg 2008: 37: 704-709

24. Hillerup S Stoltze K. Lingual nerve injury in third molar surgery I. Observations on recovery of sensation with spontaneous healing. Int J Oral Maxillofac Surg. 2007: 36:884889. 
25. Hochwald DA, Davis WH, Martinoff J. Modified distolingual splitting technique for removal of impacted mandibular third molars: incidence of postoperative sequelae. Oral Surg Oral Med Oral Pathol 1983: 56: 9-11.

26. Howe, G., Poyton, HG. Prevention of damage to the inferior dental nerve during the extraction of mandibular third molars. Br Dent J 1960: 355-363.

27. Jerjes W, Swinson B, Moles DR, El-Maaytah M, Banu B, Upile T, Kumar M, Al Khawalde M, Vourvachis M, Hadi H, Kumar S, Hopper C. Permanent sensory nerve impairment following third molar surgery: a prospective study. Oral Surg Oral Med Oral Pathol Oral Radiol Endod 2006: 102: e1-7.

28. Kipp DP, Goldstein BH, Weiss WW Jr. Dysesthesia after mandibular third molar surgery: a retrospective study and analysis of 1,377 surgical procedures. J Am Dent Assoc 1980: 100:185-92.

29. Lopes V, Mumenya R, Feinmann C, Harris M. Third molar surgery: an audit of the indications for surgery, post-operative complaints and patient satisfaction. $\mathrm{Br} \mathrm{J}$ Oral Maxillofac Surg 1995: 33: 33-35.

30. Mason DA. Lingual nerve damage following lower third molar surgery. Int $\mathrm{J}$ Oral Maxillofac Surg 1988: 17:290-294.

31. Middlehurst RJ, Barker GR, Rood JP. Postoperative morbidity with mandibular third molar surgery: a comparison of two techniques. J Oral Maxillofac Surg 1988: 46: 474-476.

32. Miura K, Kino K, Shibuya T, Hirata Y, Shibuya T, Sasaki E, Komiyama T, Yoshimasu H, Amagasa T. Nerve paralysis after third molar extraction. Kokubyo Gakkai Zasshi 1998: 65: $1-5$.

33. Obiechina AE. Paraesthesia after mandibular third molar extractions in Nigerians. Odontostomatol Trop. 1990:13: 113-114

34. Pichler JW, Beirne OR. Lingual flap retraction and prevention of lingual nerve damage associated with third molar surgery: a systematic review of the literature. Oral Surg Oral Med Oral Pathol Oral Radiol Endod 2001: 91:395-401.

35. Pogrel MA, Goldman KE. Lingual flap retraction for third molar removal. J Oral Maxillofac Surg 2004: 62: 1125-1130. 
36. Queral-Godoy E, Figueiredo R, Valmaseda-Castellon E, Berini-Aytes L, Gay-Escoda C. Frequency and evolution of lingual nerve lesions following lower third molar extraction. $\mathrm{J}$ Oral Maxillofac Surg 2006: 64:402-407.

37. Queral-Godoy E, Valmaseda-Castellon E, Berini-Aytes L, Gay-Escoda C. Incidence and evolution of inferior alveolar nerve lesions following lower third molar extraction. Oral Surg Oral Med Oral Pathol Oral Radiol Endod 2005: 99 :259-264.

38. Rehman K, Webster K, Dover MS. Links between anaesthetic modality and nerve damage during lower third molar surgery. Br Dent J. 2002: 193:43-45

39. Renton T, McGurk M. Evaluation of factors predictive of lingual nerve injury in third molar surgery. Br J Oral Maxillofac Surg 2001: 39: 423-428.

40. Robinson PP, Loescher AR, Smith KG. The effect of surgical technique on lingual nerve damage during lower 3rd molar removal by dental students. Eur J Dent Educ. 1999: 3: 5255 .

41. Robinson PP, Smith KG. Lingual nerve damage during lower third molar removal: a comparison of two surgical methods. Br Dent J 1996: 180: 456-461.

42. Rood JP. Lingual split technique. Damage to inferior alveolar and lingual nerves during removal of impacted mandibular third molars. Br Dent J 1983: 154: 402-403.

43. Rood JP. Permanent damage to inferior alveolar and lingual nerves during the removal of impacted mandibular third molars. Comparison of two methods of bone removal. Br Dent J 1992: 172: 108-110.

44. Rud J. The split-bone technic for removal of impacted mandibular third molars. J Oral Surg 1970: 28: 416-421.

45. Rud J. Reevaluation of the lingual split-bone technique for removal of impacted mandibular third molars. J Oral Maxillofac Surg 1984: 42: 114-117.

46. Schultze-Mosgau S, Reich RH. Assessment of inferior alveolar and lingual nerve disturbances after dentoalveolar surgery, and of recovery of sensitivity. Int $\mathrm{J}$ Oral Maxillofac Surg 1993: 22: 214-217.

47. Sisk AL, Hammer WB, Shelton DW, Joy ED Jr. Complications following removal of impacted third molars: the role of the experience of the surgeon. J Oral Maxillofac Surg 1986: 44: 855-859. 
48. Smith AC, Barry SE, Chiong AY, Hadzakis D, Kha SL, Mok SC, Sable DL. Inferior alveolar nerve damage following removal of mandibular third molar teeth. A prospective study using panoramic radiography. Aust Dent J 1997: 42:149-152.

49. Swanson AE. Incidence of inferior alveolar nerve injury in mandibular third molar surgery. J Can Dent Assoc. 1991: 57: 327-328.

50. To EW, Chan FF. Lingual nerve retractor. Br J Oral Maxillofac Surg 1994: 32:125-126.

51. Valmaseda-Castellon E, Berini-Aytes L, Gay-Escoda C. Inferior alveolar nerve damage after lower third molar surgical extraction: a prospective study of 1117 surgical extractions. Oral Surg Oral Med Oral Pathol Oral Radiol Endod 2001: 92:377-383.

52. Valmaseda-Castellon E, Berini-Aytes L, Gay-Escoda C Lingual nerve damage after third lower molar surgical extraction. Oral Surg Oral Med Oral Pathol Oral Radiol Endod. 2000: 90: $567-573$

53. van Gool AV, Ten Bosch JJ, Boering G. Clinical consequences of complaints and complications after removal of the mandibular third molar. Int J Oral Surg 1977: 6:29-37.

54. Visintini E, Angerame D, Costantinides F, Maglione M. Peripheral neurological damage following lower third molar removal. A preliminary clinical study. Minerva Stomatol 2007: 56: 319-326.

55. Walters H. Reducing lingual nerve damage in third molar surgery: a clinical audit of 1350 cases. Br Dent J 1995:178:140-144.

56. Winter GB. Impacted Mandibular Third Molar. St Louis, MO, American Medical Book, 1926.

57. Wofford DT, Miller RI. Prospective study of dysesthesia following odontectomy of impacted mandibular third molars. J Oral Maxillofac Surg 1987: 45:15-19. 


\section{TABLES}

Table 1. Pattern of impaction of lower third molars $(\mathrm{n}=4338)$

\begin{tabular}{|c|c|c|}
\hline Pattern of impaction & Frequency (\%) & Mean depth (SD) [mm] \\
\hline Mesioangular & $2077(47.9 \%)$ & $5.0(2.8)$ \\
\hline Horizontal & $1128(26.0 \%)$ & $6.5(3.1)$ \\
\hline Distoangular & $465(10.7 \%)$ & $4.5(3.1)$ \\
\hline Vertical & $668(15.4 \%)$ & $3.0(2.9)$ \\
\hline
\end{tabular}

Table 2. Incidence of neurosensory deficits by type of impaction

\begin{tabular}{ccc}
\hline & Inferior alveolar nerve & Lingual nerve* $^{*}$ \\
\hline Mesioangular & $0.29 \%(6 / 2077)$ & $0.53 \%(11 / 2077)$ \\
Horizontal & $0.44 \%(5 / 1128)$ & $0.53 \%(6 / 1128)$ \\
Distoangular & $0.65 \%(3 / 465)$ & $1.9 \% *(9 / 465)$ \\
Vertical & $0.15 \%(1 / 668)$ & $0.60 \%(4 / 668)$ \\
\hline Total & $0.35 \%(15 / 4338)$ & $0.69 \%(30 / 4338)$ \\
$* p<0.001$, chi-square test &
\end{tabular}


Table 3. Incidence of neurosensory deficits and mean depth of impaction, by type of operator

\begin{tabular}{|c|c|c|c|}
\hline & Inferior alveolar nerve & Lingual nerve* & $\begin{array}{l}\text { Mean depth of impaction } \\
\text { (S.D.) }[\mathrm{mm}] * *\end{array}$ \\
\hline Undergraduate & $4(26.7 \%)$ & $23(76.7 \%)$ & $4.4(2.8)$ \\
\hline Junior resident & $3(20.0 \%)$ & $3(10.0 \%)$ & $5.0(3.0)$ \\
\hline $\begin{array}{c}\text { OMS } \\
\text { postgraduate }\end{array}$ & $8(53.3 \%)$ & $3(10.0 \%)$ & $7.4(3.5)$ \\
\hline Specialist & 0 & $1(3.3 \%)$ & $4.8(3.0)$ \\
\hline Total & $15(100 \%)$ & $30(100 \%)$ & \\
\hline
\end{tabular}

${ }^{*} p<0.01, * * p<0.001,1$-way ANOVA 
Table 4. Pattern of recovery from inferior alveolar nerve deficits after lower third molar surgery $(n=15)$

\begin{tabular}{|l|c|c|c|}
\hline & No improvement & Some improvement & Total recovery (\%) \\
\hline 1st month & $2 / 15$ & $11 / 15$ & $2 / 15(13.0 \%)$ \\
\hline 3rd month & $1 / 15$ & $7 / 15$ & $7 / 15(46.7 \%)$ \\
\hline 6th month & $2 / 15$ & $5 / 15$ & $8 / 15(53.3 \%)$ \\
\hline 1st year & $3 / 15$ & $3 / 15$ & $9 / 15(60.0 \%)$ \\
\hline 2nd year & $5 / 15$ & 0 & $10 / 15(66.7 \%)$ \\
\hline >2 years & $5 / 15$ & 0 & $10 / 15(66.7 \%)$ \\
\hline
\end{tabular}

Table 5. Pattern of recovery from lingual nerve deficits after lower third molar surgery $(\mathbf{n}=\mathbf{2 6})$

\begin{tabular}{|l|c|c|c|}
\hline & No improvement & Some improvement & Total recovery (\%) \\
\hline 1st month & $5 / 26$ & $16 / 26$ & $5 / 26(19.2 \%)$ \\
\hline 3rd month & $5 / 26$ & $13 / 26$ & $8 / 26(30.8 \%)$ \\
\hline 6th month & $7 / 26$ & $4 / 26$ & $15 / 26(57.7 \%)$ \\
\hline 1st year & $8 / 26$ & $1 / 26$ & $17 / 26(65.4 \%)$ \\
\hline 2nd year & $7 / 25^{*}$ & 0 & $18 / 25(72.0 \%)$ \\
\hline >2 years & $7 / 25$ & 0 & $18 / 25(72.0 \%)$ \\
\hline
\end{tabular}

* 1 patient underwent re-anastomosis of the lingual nerve in the postoperative 13 th month and was excluded from further analysis 
Table 6. Summary of published prospective studies on neurosensory deficit after lower third molar surgery

\begin{tabular}{|c|c|c|c|c|c|}
\hline Reference & Author & Country & Sample size & $\begin{array}{l}\text { IAN } \\
\text { deficit }\end{array}$ & $\begin{array}{l}\text { LN } \\
\text { deficit }\end{array}$ \\
\hline 1 & Absi and Shepherd & UK & 110 & $0.91 \%$ & $4.6 \%$ \\
\hline 3 & Appiah-Anane and Appiah-Anane & UK & 504 & & $0.20 \%$ \\
\hline 4 & Bataineh & Jordan & 741 & $3.9 \%$ & $2.6 \%$ \\
\hline 5 & Bell & UK & 300 & 0 & $0.33 \%$ \\
\hline 6 & Benediktsdottir et al. & Iceland & 388 & $0.52 \%$ & $0.52 \%$ \\
\hline 7 & Berge and Boe & Norway & 204 & $0.49 \%$ & $0.49 \%$ \\
\hline 8 & Black & New Zealand & 3848 & $1.2 \%$ & $0.90 \%$ \\
\hline 9 & Blackburn and Bramley & UK & 1117 & & $10.5 \%$ \\
\hline 10 & Blondeau et al & Canada & 455 & & $0.66 \%$ \\
\hline 11 & Blondeau and Daniel & Canada & 550 & $1.1 \%$ & 0 \\
\hline 13 & Bruce RA et al. & USA & 990 & $4.4 \%$ & $1.1 \%$ \\
\hline 14 & Carmichael and McGowan & UK & 1339 & $3.9 \%$ & $10.7 \%$ \\
\hline 18 & Gargallo- Albiol et al. & Spain & 300 & & $1.3 \%$ \\
\hline 19 & Goldberg et al. & USA & 500 & $0.60 \%$ & $0.60 \%$ \\
\hline 20 & Gomes et al. & Brazil & 110 & & $4.6 \%$ \\
\hline 21 & Greenwood et al. & UK & 300 & & $10.7 \%$ \\
\hline 22 & Gulicher and Gerlach & Germany & 1106 & $3.6 \%$ & $2.1 \%$ \\
\hline 25 & Hochwald et al. & USA & 598 & $2.5 \%$ & $4.3 \%$ \\
\hline 27 & Jerjes et al. & UK & 1087 & $4.1 \%$ & $6.5 \%$ \\
\hline 29 & Lopes et al. & UK & 1105 & $8.4 \%$ & \\
\hline 30 & Mason DA & UK & 1040 & & $11.5 \%$ \\
\hline 31 & Middlehurst et al & UK & 60 & 0 & 0 \\
\hline 33 & Obiechina & Nigeria & 367 & $0.82 \%$ & $0.27 \%$ \\
\hline 35 & Pogrel and Goldman & USA & 250 & & $1.6 \%$ \\
\hline 38 & Rehman et al. & UK & 614 & $3.3 \%$ & $4.2 \%$ \\
\hline 39 & Renton and McGurk & UK & 2134 & & $1.6 \%$ \\
\hline 40 & Robnison PP et al. & UK & 200 & & $2.0 \%$ \\
\hline 41 & Robinson and Smith & UK & 771 & & $3.8 \%$ \\
\hline 42 & Rood & UK & 790 & $7.6 \%$ & $8.9 \%$ \\
\hline 43 & Rood & UK & 1400 & $5.5 \%$ & $6.6 \%$ \\
\hline 48 & Smith et al. & Australia & 479 & $5.2 \%$ & \\
\hline 49 & Swanson & Canada & 100 & $5.0 \%$ & 0 \\
\hline 51 & Valmaseda-Castellon et al. & Spain & 1117 & $1.3 \%$ & \\
\hline 52 & Valmaseda-Castellon et al. & Spain & 1117 & & $2.0 \%$ \\
\hline 57 & Wofford and Miller & USA & 576 & $2.6 \%$ & $0.69 \%$ \\
\hline
\end{tabular}

